\title{
ESTUDO ESTRUTURAL DAS REPRESENTAÇÕES SOCIAIS DO TRABALHO NOTURNO DAS ENFERMEIRAS ${ }^{1}$
}

\author{
Kátia Conceição Guimarães Veiga², Josicélia Dumêt Fernandes ${ }^{3}$, Mirian Santos Paiva ${ }^{4}$
}

\footnotetext{
${ }^{1}$ Artigo extraído da tese - Trabalho noturno: representações sociais de enfermeiras de um hospital público de ensino, apresentada à Escola de Enfermagem (EE) da Universidade Federal da Bahia (UFBA), 2009.

${ }^{2}$ Doutora em Enfermagem. Professora da EE/UFBA. Bahia, Brasil. E-mail: katiacgveiga@gmail.com

${ }^{3}$ Doutora em Enfermagem. Professora Titular da EE/UFBA. Pesquisadora do CNPq. Bahia, Brasil. E-mail: dumet@ufba.br

${ }^{4}$ Doutora em Enfermagem. Professora da EE/UFBA. Bahia, Brasil. E-mail: mirian@ufba.br
}

RESUMO: Estudo descritivo e analítico, com abordagens quantitativa e qualitativa, objetivando apreender as representações sociais construídas por enfermeiras sobre o trabalho noturno, através da determinação do núcleo central e sistema periférico. Foram coletadas evocações livres, produzidas por 25 enfermeiras de um hospital de ensino da rede pública, na cidade de Salvador, Bahia, Brasil, em 2008/1, a partir da expressão indutora Trabalho Noturno da Enfermeira, e submetidos à análise do quadro de quatro casas. Os resultados evidenciaram a estrutura da Representação Social, tendo como elementos centrais: responsabilidade, árduo, estressante, sofrimento e autonomia; e como elementos periféricos: ética, necessidade financeira, dupla jornada, sobrecarga e iniciativa. Estes resultados indicam a necessidade de reflexões para o desenvolvimento de estratégias que contribuam para as políticas de gestão de pessoal, considerando a especificidade, a subjetividade e a complexidade do trabalho noturno.

DESCRITORES: Enfermagem. Trabalho noturno. Representações sociais.

\section{STRUCTURAL STUDY OF THE SOCIAL REPRESENTATIONS OF NOCTURNAL NURSING WORK OF NURSES}

\begin{abstract}
This cross-sectional study with quantitative and qualitative approaches, seeks to apprehend social representations from nurses about working night shifts through identifying the central core and peripheral system. Free evocations produced by 25 nurses from a public university hospital in Salvador, Bahia, Brazil, in January of 2008 were collected from the inducing expression, "Nurse's Night Work" and subjected to the four houses framework analysis. The results showed the social representations structure with the following central elements: responsibility, arduous, stressful, suffering, and autonomy. Its peripheral elements were ethics, financial need, double shift, overload, and initiative. These results indicate the need for reflection in order to develop strategies which contribute to personnel management policies considering the specificity, subjectivity, and complexity of nocturnal work.
\end{abstract}

DESCRIPTORS: Nursing. Nocturnal work. Social representations.

\section{ESTUDIO ESTRUCTURAL DE LAS REPRESENTACIONES SOCIALES DEL TRABAJO NOCTURNO DE LAS ENFERMERAS}

RESUMEN: Estudio descriptivo y analítico, con enfoques cuantitativo y cualitativo, a fin de aprehender las representaciones sociales de las enfermeras sobre el trabajo nocturno, por medio de la determinación del núcleo central y del sistema periférico. Se recolectaron evocaciones libres producidas por las veinticinco enfermeras de un hospital universitario de la red pública, en Salvador, Bahía, Brasil, en 2008/1, a partir de la expresión inductora: el trabajo nocturno de la enfermera, y se examinaron según el análisis del marco de las cuatro casas. Los resultados mostraron la estructura de la Representación Social que tiene como núcleo central: responsabilidad, agotador, estresante, sufrimiento y autonomía, y como elementos periféricos: ética, necesidad financiera, doble jornada, sobrecarga e iniciativa. Estos resultados muestran la necesidad de una reflexión de las enfermeras para desarrollar estrategias de trabajo que contribuyan a las políticas de personal teniendo en cuenta la especificidad, la subjetividad y la complejidad del trabajo nocturno.

DESCRIPTORES: Enfermería. Trabajo nocturno. Representaciones sociales. 


\section{INTRODUÇÃO}

O trabalho se constitui num fenômeno de grande importância na vida das pessoas e no desenvolvimento das sociedades, contribuindo para a sobrevivência dessas e dos grupos humanos, bem como, na construção e transformação do mundo em que se vive.

Como construção social, o trabalho adquiriu, ao longo da história humana, diferentes significados, determinados por fatores políticos, sociais e culturais, além de outros próprios da história individual, tais como aspectos sóciodemográficos, socialização e características do contexto laboral.

O significado do trabalho se amplia e se torna mais complexo no âmbito da cultura e da sociedade em que é produzido, influenciando e condicionando a conduta das pessoas que constituem essa sociedade e os grupos sociais que a formam. Do mesmo modo, são relevantes os processos através dos quais, a sociedade e suas instituições transmitem valores e crenças acerca do trabalho, e o socializam com seus membros, em uma determinada cultura, assumindo um papel fundamental na sociedade, por ser um elemento de integração social. ${ }^{1}$

O conhecimento sobre o trabalho é adquirido a partir das experiências laborais e de informações e modelos culturais que os sujeitos recebem da sociedade, não só por meio da educação, como também, através da comunicação e interação socialmente elaboradas e compartilhadas, adquirindo diferentes significados resultantes também do conhecimento do senso comum de um determinado grupo social ou de uma parcela dessa realidade. ${ }^{1}$

Na modernidade, os seres humanos têm dificuldade em dar sentido à sua vida, se não for pelo trabalho, pois este se constitui num direito, através do qual os indivíduos criam, entram em relação com os outros, com o seu tempo e mundo, tornando-se reconhecido. ${ }^{2} \mathrm{O}$ trabalho é, portanto, o modo como os seres humanos produzem e reproduzem suas existências, estabelecendo relações sociais e objetivando sua subjetividade, sendo, destarte, uma realidade social, fruto da comunicação e interação da vida humana em sociedade. ${ }^{3}$

$\mathrm{Na}$ enfermagem, o significado do trabalho abrange, além das experiências da prática cotidiana, os aspectos técnicos, administrativos e sociais para o processo de cuidar e gerenciar, inseridos no contexto de atenção à saúde, onde estão incluídos a es- trutura, a organização e o conhecimento gerado por esse processo. O trabalho em enfermagem é, pois, entendido como a forma de desenvolver atividades relacionadas ao processo de cuidar, incluindo as atividades administrativas, fundamentadas no conhecimento específico, para atingir a excelência do cuidado, assegurando a qualidade da assistência.

No âmbito hospitalar, o trabalho na enfermagem caracteriza-se por ser contínuo, com atividades ininterruptas durante as 24 horas, distribuídas em turno diurno e noturno, e realizados cotidianamente, incluindo os finais de semana, feriados e dias santificados.

Trabalho Noturno (TN) é definido como aquele realizado durante um período de, pelo menos, sete horas consecutivas, englobando o intervalo entre meia-noite e cinco horas da manhã; e trabalhador noturno, o assalariado que executa um número considerável de horas de trabalho à noite, ao longo do ano, sendo este trabalho fixado pela legislação de cada país. ${ }^{4}$

No Brasil, consta na Consolidação das Leis do trabalho - Art.73 $\S 2^{\circ}$ da Lei ${ }^{\circ} 5.452$ de $1^{\circ}$ de maio de 1943 - que o TN é aquele compreendido entre as 22 horas de um dia até as cinco horas do dia subsequente. ${ }^{5} \mathrm{Na}$ enfermagem, a escala de horários está organizada, na maioria das organizações hospitalares, em turnos de seis horas diurnas e 12 horas noturnas.

A partir da nossa experiência profissional como enfermeiras e docentes de enfermagem, durante o ensino clínico num hospital universitário, observamos aspectos complexos e subjetivos enfrentados pelas enfermeiras* que desenvolvem atividades no período noturno, as quais, com frequência, queixavam-se das condições de trabalho, informando que a instituição, neste turno, reduz drasticamente a oferta de serviços, em geral, tais como de manutenção, bioimagem, laboratório, entre outros, e de recursos que viabilizam a assistência de enfermagem, como quantidade de profissionais e materiais, em detrimento das reais necessidades de atendimentos à clientela assistida, dificultando a realização da assistência nesse turno de trabalho.

Observamos, ainda, que essa realidade gerava descontentamentos e conflitos entre a equipe, pois, estas trabalhadoras pareciam sentir-se desprotegidas e distanciadas do grupo, entendendo que as suas queixas e reclamações não eram consideradas importantes, e, consequentemente, que o seu trabalho não era valorizado.

\footnotetext{
* Neste estudo, os sujeitos serão denominados "enfermeiras", considerando a maioria das mesmas na organização estudada.
} 
Preocupadas com essa realidade, optamos pelo desenvolvimento do presente estudo, buscando proporcionar à enfermeira do $\mathrm{TN}$, a oportunidade de expressar sua visão acerca desse trabalho, a partir de sua vivência profissional, durante o desenvolvimento de suas atividades laborais, objetivando apreender as Representações Sociais (RSs) das enfermeiras de um hospital público de ensino, na cidade de Salvador-Bahia, sobre o TN, através da determinação do Núcleo Central (NC) e do Sistema Periférico (SP).

Entende-se por RS um sistema de referência que permite a interpretação dos acontecimentos reais, dando sentido à vivência profissional, como ferramenta indispensável à identificação dos aspectos cognitivos, afetivos, sociais e simbólicos do conhecimento do senso comum, através da comunicação e interação social. ${ }^{6-7}$

Esse conhecimento refere-se ao pensamento das massas, ao qual se atribui uma lógica na organização psicológica autônoma. Seus pressupostos consideram o comportamento social como simbólico, enquanto atividade produzida pelos processos de comunicação e influência do contexto das relações interpessoais e grupais. Ressalta-se que a RS é uma instância intermediária entre conceito e percepção, situando-se sobre as dimensões de atitudes, informações e de imagens, que contribui para a formação de condutas e orientação das comunicações sociais, conduzindo aos processos de objetivação e de ancoragem, além de caracterizar uma focalização sobre a relação social e a pressão à inferência. ${ }^{8}$

Na perspectiva da Teoria do Núcleo Central (TNC), as RSs possuem conteúdos sujeitos a uma estrutura hierarquizada, ${ }^{9}$ formada por dois sistemas de significados, um central ou NC, rígido, coerente, estável e consensual, definidor da homogeneidade do grupo e ligado a sua história coletiva; e o SP, cujos elementos são mais flexíveis e sensíveis ao contexto, integrando as experiências individuais, sendo nele que se manifesta a heterogeneidade do grupo. O sistema central determina a organização da representação e gera a significação dos elementos da mesma, enquanto que o SP é responsável pela adaptação contextual da representação e proteção do núcleo central. ${ }^{10}$

A RS é elaborada a partir dos fenômenos comunicacionais, repercutindo sobre as interações e mudanças sociais. A comunicação social, por sua vez, é responsável pela formação do processo representacional, estruturado em três âmbitos: o cognitivo, pelo acesso desigual às informações de interesses ou implicação dos sujeitos, bem como a necessidade de agir em relação aos outros; a formação da RS, através dos processos de objetivação e ancoragem; e a edificação das condutas, expressas através de opiniões, atitudes e estereótipos. ${ }^{6,8}$

Desse modo, a Teoria das Representações Sociais (TRS) mostra o sujeito, de modo indissociável, construindo o seu mundo na tentativa de adaptação às modificações da realidade social, influenciado pela cultura, ideologia e valores, que permitem ser, os indivíduos, simultaneamente, produto e produtor da sociedade, em constante relação com o outro. ${ }^{11}$

\section{EIXO METODOLÓGICO}

Trata-se de um estudo descritivo e analítico, com abordagens quantitativa e qualitativa, utilizando-se dos aportes da $\mathrm{TRS}^{6}$ e da $\mathrm{TNC}^{7}$, no que se refere à estrutura da RS de enfermeiras sobre o $\mathrm{TN}$, num contexto hospitalar.

Apesar de a TRS indicar a utilização de métodos sistemáticos para observação, análise e compreensão do fenômeno do conhecimento do senso comum, além de multitécnicas de análise e de inovação de estratégias metodológicas, a presente investigação utilizou os dados coletados através do Teste de Associação Livre de Palavras (TALP), a partir do estímulo indutor TN da Enfermeira, por considerá-lo suficiente para o alcance do objetivo proposto.

O TALP é caracterizado como um teste projetivo, que permite a apreensão das projeções mentais de um grupo social de maneira espontânea e descontraída, revelando os conteúdos implícitos ou latentes que podem estar mascarados nas produções discursivas, possibilitando estudar os estereótipos sociais que são partilhados espontaneamente pelos membros do grupo e a visualização das dimensões estruturantes do universo semântico específico. ${ }^{12}$

A amostra foi constituída por 25 (89,3\%) enfermeiras do serviço de assistência intermediária de um hospital da rede pública de ensino, na cidade do Salvador-Bahia, escolhido por ser referência na formação de recursos humanos em saúde. Os critérios de inclusão na amostra foram ter vínculo permanente com a instituição; estar em efetivo exercício no período de coleta de dados, independentemente do turno de trabalho; ter, pelo menos, um ano de trabalho na instituição, tempo tido como necessário para o estabelecimento da interação social neste grupo de trabalhadoras, possibilitando assim, a elaboração das RSs; e aceitar participar do estudo.

Na coleta de dados, foi solicitado às enfermeiras, individualmente, a evocação de cinco palavras ou expressões em resposta ao estímulo indutor e 
registradas na ordem em que foram emitidas pelas pesquisadoras, em ficha própria. Foram respeitadas todas as orientações da Resolução 196/96 do Conselho Nacional de Saúde ${ }^{13}$, inclusive, aprovação do Comitê de Ética em Pesquisa da organização onde a pesquisa foi realizada, sob protocolo $\mathrm{n}^{\circ} 070 / 2007$.

Os dados, coletados durante os meses de abril e maio de 2008, foram analisados através do Software EVOC ${ }^{14}$, o qual realiza cálculos estatísticos e informa a frequência e ordem média das evocações livres das palavras, as quais servem de base à construção do quadro de quatro casas/quadrantes, sendo dois superiores (direito e esquerdo) e dois inferiores (direito e esquerdo).

Os elementos que fazem parte do primeiro quadrante superior esquerdo desse quadro são os prováveis elementos do $\mathrm{NC}$, pois apresentam maior frequência e pronta evocação, enquanto os elementos do SP estão situados no quadrante inferior direito. Os elementos do quadrante superior direito, considerados de primeira periferia, podem migrar, não só para o quadrante do NC, como para aquele do SP. 7,12,15

Os elementos do quadrante inferior esquerdo são elementos intermediários, situados entre o NC e o SP da representação, não analisáveis pela TNC devido a controvérsias entre os estudiosos da teoria, que atribuem esses encargos à Grande Teoria das Representações Sociais. ${ }^{7,12,15}$

Buscando restaurar o conteúdo da estrutura representacional do $\mathrm{TN}$ da enfermeira, que está relacionado a uma série de significados, estes foram reconstruídos e ordenados de acordo com o lugar que ocupam na estrutura da representação, utilizando outros termos complementares com significados similares. Desse modo, foram identificadas duas categorias centrais e duas periféricas. Como catego- rias centrais: Trabalho noturno da enfermeira como trabalho de responsabilidade e Trabalho noturno da enfermeira como trabalho árduo. Como categorias periféricas: Trabalho noturno da enfermeira como trabalho de iniciativa e Trabalho noturno da enfermeira como necessidade financeira.

\section{RESULTADOS E DISCUSSÃO}

Participaram deste estudo 25 enfermeiras do serviço de assistência intermediária, correspondendo a $89,3 \%$ do total de enfermeiras do grupo estudado na organização; 21 eram do sexo feminino e quatro do sexo masculino. Em relação ao turno de serviço, 16 trabalhavam no turno diurno e nove no período noturno. Do total de profissionais estudados, 18 informaram realizar outra atividade remunerada, sendo que 17 delas na área de enfermagem; sete disseram ter um único vínculo empregatício. Quando considerado o outro vinculo empregatício, 12 trabalhavam apenas no período diurno, 12 nos turnos diurno e noturno simultaneamente, e apenas uma trabalhava exclusivamente à noite, apesar de ter dois vínculos empregatícios.

Do total dos 25 sujeitos, foram evocados 123 termos, que, após serem desprezados os termos evocados apenas uma vez, a fim de tornar mais consistente e representativa a análise, resultaram num corpus de 119 termos evocados (96,7\%). Destes, 23 com significados diferentes, a partir do estímulo indutor Trabalho Noturno da Enfermeira. Foi obtida frequência média final por palavra de 5,41 e ordem média de evocações de 2,93, o que possibilitou a construção das linhas que dividem o quadro em quatro quadrantes, onde os eixos vertical e horizontal referem-se, respectivamente, à frequência média e à ordem média de evocação, constituindo-se na base de análise, apresentada a seguir, no quadro 1 .

Quadro 1 - Visualização do núcleo central e sistema periférico do trabalho noturno de enfermeiras. Salvador-BA, 2008

\begin{tabular}{|c|c|c|c|c|c|c|}
\hline & \multicolumn{3}{|c|}{ Ordem média de evocação $<2,9$} & \multicolumn{3}{|c|}{ Ordem média de evocação $\geq 2,9$} \\
\hline \multirow{5}{*}{ Freq. $\geq 5$} & Responsabilidade & 10 & 2,200 & Desgastante & 13 & 3,077 \\
\hline & Árduo & 9 & 2,444 & Assistência & 12 & 3,500 \\
\hline & Estressante & 8 & 2,375 & Dedicação & 7 & 3,143 \\
\hline & Sofrimento & 8 & 2,625 & Administração & 5 & 3,000 \\
\hline & Autonomia & 7 & 2,857 & Conhecimento & 5 & 3,800 \\
\hline \multirow{5}{*}{ Freq. $<5$} & Continuidade & 4 & 1,750 & Ética & 4 & 3,000 \\
\hline & Tranquilidade & 3 & 1,667 & Necessidade financeira & 4 & 3,750 \\
\hline & Marginalização & 3 & 2,333 & Dupla-jornada & 3 & 3,667 \\
\hline & & & & Sobrecarga & 3 & 3.333 \\
\hline & & & & Iniciativa & 3 & 4,000 \\
\hline
\end{tabular}


Conforme se observa no quadro 1 , os elementos responsabilidade, árduo, estressante, sofrimento e autonomia estão no quadrante superior esquerdo, constituindo-se nos principais elementos, por terem sido prontamente evocados e com maior frequência, indicando que fazem parte do NC das RSs do TN das enfermeiras, sujeitos deste estudo.

Considerando que uma representação é constituída por um conjunto de informações, crenças, opiniões e atitudes a respeito de certo objeto social, organizado e estruturado num sistema sóciocognitivo específico, destaca-se ser o NC determinado pela natureza do objeto representado, no caso, o TN da enfermeira, pelo tipo de relação que o grupo estudado mantém com o objeto e pelo sistema de valores e normas que constituem o seu contexto ideológico, tendo ele uma dimensão qualitativa de dar significado à representação. ${ }^{7}$

Os elementos responsabilidade e autonomia estão explicitados no Código de Ética dos Profissionais de Enfermagem, no seu Capítulo I, que trata dos Princípios Fundamentais, para o exercício da profissão. ${ }^{16}$ A responsabilidade é definida como a capacidade ou habilidade de responder ou assumir o que fazemos no mundo, em uso pleno de nossa liberdade, sendo esta constitutiva das pessoas e se impondo pela consciência do que fazemos. ${ }^{17}$

A tríade consciência, liberdade e responsabilidade são qualidades humanas inseparáveis, que só podem ser compreendidas como manifestação do ser humano no mundo. ${ }^{17}$ As RSs, por sua vez, são uma forma de saber social que serve para agir no mundo. ${ }^{19}$

As enfermeiras no TN assumem, pois, a responsabilidade perante a organização, seu grupo de trabalho e pacientes, pela prestação da assistência de enfermagem dentro do contexto organizacional, sendo ela requerida a todo instante para a tomada das decisões necessárias ao processo de cuidar.

A autonomia, elemento também constituinte do NC das RSs das enfermeiras sobre o TN, configura-se como um dos quatro princípios da Bioética, assim como, a beneficência, a não-maleficência e a justiça; significa autogoverno, autodeterminação da pessoa para tomar decisões, estando associado "[...] à capacidade do ser humano decidir o que é bom ou que é seu bem-estar $[. . .]^{\prime \prime} .{ }^{19: 15}$

Os elementos árduo, estressante e sofrimento, podem ser, em parte, justificados pela longa jornada, uma das características desse turno de trabalho que, na maioria das organizações hospitalares, está estabelecido em turnos de doze horas consecutivas.
Nessa condição, a fadiga, como consequência da carga de trabalho desenvolvida, está relacionada aos efeitos negativos à saúde, já associados às longas jornadas de trabalho, tais como acidentes e ferimentos, distúrbios músculosesqueléticos, problemas psicológicos, estilos de vida não-saudáveis, assim como o maior risco de hipertensão e de doenças cardiovasculares. Esses elementos evocados pelas informantes apontam para a possibilidade do excesso de trabalho atuar diretamente como um agente estressor, considerado fator que pode aumentar a exposição a riscos ocupacionais, além de favorecer a ocorrência dos chamados comportamentos não-saudáveis. ${ }^{20}$

Assim, a organização do trabalho pode conduzir a situações de pressões, as quais são geradoras de estresse e podem interferir no equilíbrio psíquico do trabalhador, gerando insatisfação com o trabalho e problemas nas relações sociais do grupo. ${ }^{21}$

Além disso, a privação do sono e a desestruturação dos ritmos biológicos podem afetar a saúde do trabalhador, tanto nos aspectos físicos e psíquicos, quanto nos aspectos familiares, sociais e interpessoais. Desse modo, o trabalho noturno revela-se como uma das formas mais perversas de organização temporal do trabalho. ${ }^{21}$

Os elementos ética, necessidade financeira, dupla jornada, sobrecarga e iniciativa, situados no quadrante inferior direito, fazem parte do SP, por apresentarem menor frequência e maior média de evocação. Esse sistema é organizado pelo NC, permitindo o enraizamento e adaptação do grupo à realidade em função das vivências cotidianas que podem gerar representações mais individualizadas, constituindo componentes de sustentação e manutenção das funções do NC - geradora, organizadora e estabilizadora. ${ }^{22}$

Os elementos periféricos têm como características serem prescritores de comportamentos e tomadas de posição dos sujeitos, orientando as ações e reações destes, além de possibilitarem uma modulação individualizada das representações e das condutas a elas associadas. ${ }^{7}$

As RSs podem, destarte, demonstrar os elementos resultantes não só do contexto, como do processo de comunicação inerente ao grupo em cada momento, pois cada grupo tem uma existência própria, independente das manifestações individuais. $^{15}$

Assim, percebe-se que as concepções das enfermeiras, sujeitos do presente estudo, são resultantes da experiência cotidiana construída 
através do desenvolvimento de atividades contínuas e específicas de sua prática, constituindo as categorias centrais e periféricas da estrutura representacional do $\mathrm{TN}$ da enfermeira, a saber: Trabalho noturno da enfermeira como trabalho de responsabilidade e Trabalho noturno da enfermeira como trabalho árduo. Como categorias periféricas: Trabalho noturno da enfermeira como trabalho de iniciativa e Trabalho noturno da enfermeira como necessidade financeira.

Trabalho noturno da enfermeira como trabalho de responsabilidade - Essa categoria foi definida pelas expressões autonomia, dedicação e administração, refletindo condições essenciais de trabalhadoras para o desenvolvimento das atividades de enfermagem no turno noturno. A autonomia, já discutida anteriormente, constitui-se num dos princípios éticos fundamentais para o exercício profissional da enfermeira. A dedicação, entendida como a capacidade de se entregar à realização de um objetivo ou trabalho, parece se constituir numa condição ao exercício da enfermagem, fazendo parte da construção histórico-social da profissão e do TN, uma vez que este foi representado por esta. A administração, por sua vez, é função privativa da enfermeira, definida no Código de Ética dos Profissionais de Enfermagem, ${ }^{16}$ e na Lei ${ }^{\circ}$ 7.498/86, que dispõe sobre a regulamentação do exercício da Enfermagem. ${ }^{23}$

Trabalho noturno da enfermeira como trabalho árduo - Categoria determinada pelas expressões desgastante, sofrimento e estressante, que demonstram o verdadeiro significado e a natureza do $\mathrm{TN}$ da enfermeira para as informantes.

O TN da enfermeira é singular não só pela enfermagem caracterizar-se como profissão essencialmente integrada por mulheres como, também, pela condição de permitir combinar diferentes jornadas de trabalho. As enfermeiras convivem com a dinâmica das organizações no desenvolvimento de suas atividades laborais e, ao mesmo tempo, gerenciam suas vidas como pessoas, esposas, mães, filhas e outros tantos papéis sociais que assumem na condição de mulher. Desse modo, a intensidade da vivência que a enfermeira experimenta no seu cotidiano de TN lhe exige uma contínua e profunda mobilização de energias, que vão desde a privação do sono à desestruturação dos ritmos biológicos, que podem afetar a sua saúde, tanto nos aspectos físicos e psíquicos, quanto nos aspectos familiares, sociais e interpessoais.

As trabalhadoras de enfermagem, na nossa realidade, se dividem entre duplas e até triplas jornadas de trabalho, considerando as horas de trabalho doméstico, sendo comum encontrar trabalhadoras que vêm de outra instituição para cumprir mais uma jornada de trabalho, sem intervalos para repouso/alimentação, entre outras necessidades. Tal sobrecarga ocasionada pelo acúmulo de jornadas parece ser justificada, pela inserção da mulher no mercado de trabalho, o qual não a desvincula das tarefas domésticas e da educação dos filhos, resultando num acúmulo de atribuições, que podem conduzi-la ao estresse. ${ }^{24}$

As trabalhadoras que realizam tarefas arriscadas para a sua saúde, como os da enfermagem, que trabalham em turnos, se submetem aos horários alternados e são expostas ao contínuo confronto com a fragilidade da vida, estão mais susceptíveis ao sofrimento, tanto do corpo como da mente, gerando estresse e tornando o trabalho árduo. ${ }^{25}$

Trabalho noturno da enfermeira como trabalho de iniciativa - Categoria determinada, na concepção das informantes, pelas expressões conhecimento, ética e assistência, constituindo-se em condição e atitude positiva quanto ao significado do TN da enfermeira, podendo ser consideradas como requisitos necessários para tomada de decisões na consecução da assistência de enfermagem nesse turno de trabalho, em particular, que no modelo clínico de atenção à saúde individual.

A tomada de decisão no trabalho da enfermeira se apresenta vinculada à responsabilidade e conhecimentos adquiridos pelas profissionais ao longo de sua experiência de vida e de trabalho diante das transformações do mundo, como produto do processo de interação e comunicação social, o que implica na necessidade de constantes atualizações frente aos avanços nas ciências da saúde, assegurando a qualidade da assistência à clientela sob a sua responsabilidade.

Trabalho noturno da enfermeira como necessidade financeira - Categoria definida pelas expressões dupla-jornada e sobrecarga, refletindo o interesse das enfermeiras, sujeitos deste estudo, pela escolha do TN, considerando o acréscimo da remuneração de, pelo menos, $20 \%$ da hora noturna sobre a hora diurna ${ }^{5}$, e a possibilidade de combinar dupla jornada de trabalho, uma vez que a política econômica da área de saúde, cujos salários são insuficientes para o sustento da família, as leva a procurar outras fontes de renda. Este fato contribui para a busca de outro vínculo de trabalho. Assimé que, no cotidiano do trabalho em hospitais, é grande a procura das profissionais de enfermagem pelo 
$\mathrm{TN}$, o que pode estar relacionado com interesses financeiros, pelo acréscimo do adicional noturno, e/ou pela necessidade de conciliar atividades de ensino, vida pessoal e outros empregos. ${ }^{26}$

Os componentes das categorias centrais e periféricas, supracitadas, apontam aspectos importantes para reflexão sobre os elementos de sustentação do NC, tais como: assistência, administração, desgaste, sofrimento, estresse, dupla-jornada e sobrecarga.

Considerando que a TRS possibilita a compreensão da dimensão normativa, além dos processos de transformação dos conhecimentos partilhados por um grupo determinado acerca de uma realidade social, chamou-nos a atenção o caráter normativo das representações evocadas por este grupo de trabalhadoras. As RSs funcionam, pois, como normas grupais, definindo o que deve ou não ser considerado um dado objeto social e as características próprias de um determinado objeto que o faz ser reconhecido como este e não outro objeto. ${ }^{27}$

\section{CONSIDERAÇÕES FINAIS}

Os resultados evidenciaram que a estrutura da RS das enfermeiras sobre o TN tem como elementos centrais responsabilidade, árduo, sofrimento, estressante e autonomia, e como elementos periféricos, ética, necessidade financeira, dupla jornada, sobrecarga e iniciativa. O TN da enfermeira foi representado, portanto, como um trabalho de responsabilidade e árduo, que causa estresse e sofrimento, conferindo, porém, autonomia à enfermeira. É também um trabalho que 'se sustenta' pela necessidade financeira dessa profissional, a qual se submete à dupla jornada e consequente sobrecarga de trabalho, exigindo iniciativa e atitude ética.

Essa realidade vivenciada pelas trabalhadoras de enfermagem de modo geral e, em particular, pelas enfermeiras que se submetem à dupla ou tripla jornada de trabalho, favorece a ocorrência de acidentes de trabalho e erros técnicos, o que pode comprometer a segurança e integridade da clientela assistida, pois o TN é, preferencialmente, escolhido para combinar as jornadas de trabalho.

Por outro lado, a estruturação dos turnos de trabalho em enfermagem, com o estabelecimento de turnos de seis horas diurnas e doze horas noturnas, determina jornada de trabalho longa para este último turno, podendo causar cansaço e sofrimento à trabalhadora, uma vez que, neste horário, fisiologicamente, há a necessidade imperiosa do organismo em repousar, e, do ponto de vista social, está estabelecido horário/espaço para o convívio familiar e social, favorecendo o fortalecimento dos laços afetivos e sociais. Assim, este turno de trabalho influencia sobremaneira na vida dessas enfermeiras.

As representações apreendidas, neste estudo, se referem aos atributos e maneiras de ser ou de agir posto para as enfermeiras, de modo geral, por seu próprio grupo, confirmando que essas representações produzem normas de condutas, regulam os comportamentos, prescrevendo possibilidades de ação diante do objeto social representado, neste caso o TN da enfermeira no contexto de uma instituição hospitalar de ensino.

As enfermeiras se referem ao TN através de representações que conferem um caráter normativo a este trabalho, prescrevendo atitudes e comportamentos socialmente construídos e aceitos como próprios da categoria, enfatizando a construção histórica da profissão enquanto dedicação e responsabilidade, autonomia, entre outros, colocados num contexto normativo.

As RSs são concebidas neste estudo, portanto, como um processo social de comunicação e discurso, além de atributos individuais e estruturas de conhecimento individualmente acessíveis, onde os membros de um grupo criam o objeto representado e dão-lhe significado e realidade.

Através das RSs, os sujeitos são situados dentro de um campo social, possibilitando a elaboração de uma identidade social e individual gratificante, compatível com o sistema de normas e valores socialmente e historicamente determinados, conferindo identidade ao grupo.

As RSs, como sistemas de compreensão e interpretação da realidade, mostram-se particularmente úteis para transformar a vida cotidiana de trabalhadoras, possibilitando a ressignificação do TN.

Esses resultados conduzem à necessidade de despertar a reflexão das enfermeiras sobre essas representações, para que, em grupo, desenvolvam estratégias de trabalho voltadas para sua realidade, favorecendo um modelo de prática que considere o caráter dinâmico deste turno de serviço, propiciando o enfrentamento dos problemas cotidiano e contribuindo na elaboração de políticas de pessoal que respeitem a especificidade, subjetividade e complexidade do TN, resguardando os interesses da categoria e de sua clientela, o que irá favorecer, em alguma medida, o seu desempenho 
e o comprometimento ético-político da instituição com essa trabalhadora.

Igualmente, ressaltamos a importância da realização de novas investigações para aprofundamento dessa temática, bem como, a ampliação das discussões ainda no âmbito acadêmico.

\section{REFERÊNCIAS}

1. Peiró JM, Prieto F, Roe RA. El trabajo como fenômeno psicosocial. In: Peiró JM, Prieto F, organizadores. Tratado de psicología del trabajo.v.II: Aspectos psicosociales del trabajo. Madrid (ES): Editorial Síntesis S.A.,1996. p.15-33.

2. Albornoz S. O que é o trabalho. 6 a ed. São Paulo (SP): Brasiliense, 2004.

3. Almeida MCP, Rocha SMM. Considerações sobre a enfermagem enquanto trabalho In: Almeida $\mathrm{MCP}$, Rocha SMM, organizadores. O trabalho de enfermagem. São Paulo: Cortez, 1997, p.15-26. Cap.1

4. Organizacíon Internacional del Trabajo. Conferencia Internacional del Trabajo: el trabajo nocturno. 77ª Reunion. Ginegra, 1990 [acesso 2007 Mai 08]. Disponível em: http:/ / www.ilo.org/ilolex/cgi-lex/ pdconvs2.pl?host $=$ status01\&textbase $=$ ilospa\&docum ent $=172 \&$ chapter $=1 \&$ query $=\% 5 \mathrm{~B}+$ trabajo+nocturno $+\% 5$ D\&highlight $=$ on\&querytype $=$ bool\&context $=0$.

5. Brasil. Lei $n^{\circ} 5.452$ de $1^{\circ}$ de maio de 1943 , da Consolidação das Leis do trabalho [online]. [acesso 2007 Jul 08]. Disponível em: http:/ / www.trt02.gov. br/geral/tribunal2/legis/CLT/TITULOII.html.

6. Moscovici S. A representação social da psicanálise. Rio de Janeiro: Zahar; 1978.

7. Abric JC. A abordagem estrutural das representações sociais. In: Moreira ASP, Oliveira DC, organizadores. Estudos interdisciplinares de representações sociais. $2^{\mathrm{a}}$ ed. Goiânia (GO): AB; 2000. p.27-38.

8. Nóbrega SM. Sobre a teoria das representações sociais. In: Moreira ASP, Jesuíno JC, organizadores. Representações sociais: teoria e prática. $2^{\mathrm{a}}$ ed. João Pessoa (PB): Editora Universitária/UFPB; 2003. p.51-80.

9. Pereira FJC. Análise de dados qualitativos aplicados às representações sociais In: Moreira ASP, Camargo BV, Jesuíno JC, Nóbrega SM, organizadores. Perspectivas teórico-metodológicas em representações sociais. João Pessoa (PB): Editora Universitária/UFPB; 2005. p.25-60.

10. Vala J, Monteiro MB, coordenadores. Psicologia social. $7^{\mathrm{a}}$ ed. Lisboa (PT): Fundação Caloute Gulbenkian; 2006.

11. Paiva MS, Oliveira JF. As representações sociais e a saúde da mulher: balanço da produção do grupo de estudos sobre saúde da mulher GEM. In: Coutinho MPL, Lima AS, Oliveira FB, Fortunato ML, organizadores. Representações sociais: abordagem interdisciplinar. João Pessoa (PB): Editora Universitária/UFPB; 2003. p. 251-63.

12. Oliveira D. Análise das evocações livres: uma técnica de análise estrutural das representações sociais. In: Moreira ASP, Camargo BV, Jesuíno JC, Nóbrega SM, organizadores. Perspectivas teórico-metodológicas em representações sociais. João Pessoa (PB): Editora Universitária/UFPB; 2005. p.573-603.

13. Ministério da Saúde (BR), Conselho Nacional de Saúde, Comissão Nacional de Ética em Pesquisa. Resolução No 196 de 10 de outubro de 1996: diretrizes e normas regulamentadoras de pesquisa envolvendo seres humanos. Brasília (DF): MS; 1996.

14. Vergès $P$. Ensemble de programmes permettant l'analyse d'évocations: manuel version 2 . Aix-emProvence (FR): LAMES; 1999.

15. Sá CP. Núcleo central das representações sociais. Petrópolis (RJ): Vozes; 1996.

16. Conselho Federal de Enfermagem. Resolução COFEN 311/2007 - Código de Ética dos Profissionais de Enfermagem [online] [acesso 2008 Dez 01]. Disponível em: http://www.portalcofen.gov.br/2007/materias. asp?ArticleID $=7323 \&$ sectionID $=37$

17. Gomes JCV. Logoterapia - a psicoterapia existencial humanista de Viktor Emil Frankl. São Paulo: Edições Loyola; 1987. p.47-9.

18. Jodelet D. Experiência e representações sociais. In: Menin MSS, Shimizu AM, organizadores. Experiência e representação social: questões teóricas e metodológicas. São Paulo: Casa do Psicólogo; 2005. p.23-56.

19. Costa SIF, Oselka G, Garrafa V. Iniciação à bioética. Brasília (DF): Conselho Federal de Medicina; 1998.

20. Moreira AMR, Mendes R. Fatores de riscos dos distúrbios osteomusculares relacionados ao trabalho de enfermagem. Rev Enferm UERJ. 2005; Jan-Abr; 13(1):19-26.

21. Dejours C. Uma nova abordagem do sofrimento nas organizações In: Chaulat $\mathrm{P}$, organizadores. O indivíduo - uma dimensão esquecida nas organizações. São Paulo (SP): Atlas; 1994.

22. Abric JC. Abordagem estrutural das representações sociais: desenvolvimentos recentes. In: Campos PH, Loureiro MCS, organizadores. Representações sociais e práticas educativas. Goiânia (GO): UCG; 2003. p.37-57.(Série Didática, 8).

23. Conselho Federal de Enfermagem. Lein 7.498/86, de 25 de junho de 1986: dispõe sobre a regulamentação do exercício da Enfermagem e dá outras providências [online] [acesso 2008 Dez 02]. Disponível em: http:/ / www.portalcofen.gov.br/2007/section.asp?section ParentID $=35 \&$ sectionID $=30$.

24. Pafaro RC, De Martino MMF. Estudo do estresse do enfermeiro com dupla jornada de trabalho em um hospital de oncologia pediátrica de Campinas. Rev Esc Enferm USP. 2004; 38(2):152-60. 
25. Gonzáles RMB, Beck CLM. O sofrimento e o prazer no cotidiano dos trabalhadores da enfermagem. Texto Contexto Enferm. 2002; Jan-Mar; 11(1):169-86.

26. Magalhães AMM. Perfil dos profissionais de enfermagem do turno noturno do Hospital de Clínicas de Porto Alegre. Rev HCPA. 2007; 27(2):16-20.
27. Campos PHF. As representações sociais como forma de resistência ao conhecimento científico In: Oliveira DC, Campos PHF, organizadores. Representações sociais, uma teoria sem fronteiras. Rio de Janeiro: Editora Museu da República; 2005. p.85-98. 